\title{
Entre lienzos humanos, tabúes y expresiones plásticas
}

\author{
URI: http://hdl.handle.net/11298/284 \\ Miguel Ángel Hernández-Vásquez ${ }^{1}$ \\ Estudiante Utec \\ angeltotemics@gmail.com \\ Recibido: 07/09/16 - Aceptado: 25/09/16
}

\begin{abstract}
Resumen
La Antropología, como ciencia especializada del ser humano, estudia los elementos simbólicos que desde la etnicidad configuran el pensamiento. Esto se puede apreciar en las cosmovisiones locales dentro de la sociedad salvadoreña cuando se hace referencia a la ritualidad del tatuaje como expresión artística y como un medio de comunicación e interacción social. Dichos elementos son el eje central de este acercamiento etnográfico auxiliado de la técnica de la encuesta como préstamo al método cuantitativo. Esta última aplicada a estudiantes de la asignatura de Filosofía de la Universidad Tecnológica de El Salvador (Utec), para complementar el análisis cualitativo, como resultado de las entrevistas realizadas a los expertos culturales. Por lo tanto, el tipo de estudio es de carácter exploratorio, descriptivo y no probabilístico.
\end{abstract}

\section{Palabras clave}

Antropología simbólica; Antropología cultural-historia; Grupos étnicos; Tatuajes-Aspectos sociales.

\section{La conceptualización del tatuaje en su génesis ante el tabú}

Como parte de la concepción que guarda el tatuaje, para la Antropología y la Etnología, se identifica en el siguiente postulado de Hope Ponce \& Mora Eguiarte (2000):

\begin{abstract}
Anthropology, as a science which specializes in the human being, studies those symbolic elements that shape the human thought from ethnicity. This can be viewed in the local worldviews within the Salvadorean society when making reference to the rituality of tattooing as an artistic expression and a means of social interaction and communication. Such elements are the backbone of this ethnographic approach aided by surveys as part of the quantitative method. The survey was conducted with students from the subject of Philosophy at Universidad Tecnológica de El Salvador (Utec) in order to complement the qualitative analysis, and as a result of the interviews that were conducted with cultural experts. Therefore, the type of study is exploratory, descriptive and non-probabilistic.
\end{abstract}

\section{Keywords}

Symbolic Anthropology; Cultural Anthropology-History; Ethnic groups; Tattoos-Social aspects.

$(A)^{2}$ Escritura o dibujos que se realizan al inyectar tinta bajo la dermis, o por medio de cortes en la piel que permiten introducir hollín, tierra o carbón, y que al cicatrizar la herida quedan de forma permanente. La escritura o dibujos en la piel pueden tener fines estéticos o rituales y son muy comunes en gran parte de las culturas del mundo. Escarificación (p. 152).

\footnotetext{
${ }^{1}$ Estudiante investigador de la Licenciatura en Antropología, instructor de la cátedra de Antropología y de Realidad Nacional.

2 Antropología.
} 
Se le denomina lienzo a toda aquella superficie en la cual se plasman trazos, figuras y, por supuesto, la cromática si así fuese el diseño.

Las cosmovisiones locales y translocales, en la globalización del pensamiento humano, redirigen diferentes formas y expresiones que se entremezclan para construir nuevos híbridos culturales en las expresiones plásticas. No es de extrañarse que el dinamismo social impere sobre las culturas locales y aproxime contextos socioculturales que expresen estados de aculturación, transculturación y asimilación cultural, imponiéndose la voluntad de las clases dominantes sobre las dominadas, manteniéndose así la lucha de contrarios, tal como lo expresa el marxismo en una de sus leyes dialécticas.

En este punto es importante resaltar las diferentes etapas la experimentación del tatuaje en su proceso de incorporación a la piel:

El tatuaje se inicia al identificar el cuerpo como un lienzo vivo y sensible, como posibilidad de expresión artística que permite hablar de sí. El dolor que se experimenta al tatuarse también da sentido a la práctica. Un brazo, una pierna tatuados son totalidades que trascienden los límites de lo orgánico y cobran vida propia. El cuerpo es la expresión del sí mismo en tanto es texto pictórico, grabado en la piel, que tiene el valor de hacer presente ante los ojos, de manera permanente y para toda la vida una narración, una historia que cuenta las experiencias, sentimientos y vínculos significativos del sujeto. El tatuaje, entonces, no es una parte de sí mismo: es una síntesis del sí mismo, al identificar de manera explícita y objetiva aspectos de la subjetividad (Sastre Cifuentes, 2011).

Por otra parte, en consonancia con el tatuaje se enfoca la conceptualización del tabú como un elemento coercitivo en la práctica y difusión del tatuaje en la sociedad moderna, para lo cual se presenta el siguiente aporte de Hope Ponce \& Mora Eguiarte (2000):

Tabú: $(A S)^{3}$ (ETN) ${ }^{4}$ Palabra de origen polinesio ("tappú") que significa que esta fuera del uso corriente: un animal que no se puede tocar ni matar, una relación de matrimonio que no se puede establecer. En polinesio lo que no es "tabú" es "noa", es decir, libre, que pertenece al orden de lo común. Es el acto que no se puede realizar sin atentar contra el orden universal, que es a la vez el de la naturaleza y el de la sociedad. No se trata de una imposiblidad logica ni racional: la prohibición no es motivada por justificaciones explicables, y la sanción esperada en caso de violación no esta inscrita en un código o ley, sino que es una calamidad. incesto (p. 152).

\section{El simbolismo inmerso en la genética del tatuaje y sus dualidades}

Cada sociedad configura sus propios códigos, símbolos y significados que Max Weber y Clifford Geertz en su momento coincidieron en llamar el entramado de significados en donde el ser humano está suspendido como en una tela de araña; cada cultura y cada sujeto(a) define el horizonte que se tiene que seguir, y esa línea interminable entre cada paradigma le permite avanzar, detenerse, plantearse, replantearse, estructurar, reestructurar, deconstruir, construir y reconstruir sus cosmovisiones, de las cuales emana el conocimiento científico. Bajo estas premisas se sitúan los aportes de Leslie White, Clifford Geertz, Sperber, Mary Douglas, Víctor Turner, Edmund Leach, entre otros; sobre el carácter simbólico que emana entre cada cultura, entre los cuales se identifican los siguientes postulados:

Antropología Simbólica: (A) Se llama así a los trabajos antropológicos que tienen como objeto de estudio central lo simbólico, aunque no se puede hablar de una corriente unificada, ya que los antropólogos que trabajan lo simbólico lo entienden de distintas maneras, dependiendo de las Escuelas de origen, y existen distintas antropologías simbólicas [...] Todos aquellos antropólogos que centren su atención en el símbolo, su significado y como significa, hacen Antropología simbólica, independientemente de la forma en que la conciban (Hope Ponce \& Mora Eguiarte, 2000).

Siguiendo el recorrido teórico de la Antropología Simbólica, es importante resaltar el papel que desempeña el signo en la codificación de las abstracciones que en todo momento emplea el ser humano para comunicarse. Es importante observar e interpretar el punto clave que desempeña el signo

\footnotetext{
3 Antropología Social

${ }^{4}$ Etnología
} 
en la comunicación verbal y no verbal que desarrolla la especie humana en sus diferentes contextos históricos y culturales, del cual se distingue el siguiente postulado:

Signo: (LIN $)\left(A S^{6}\right)\left(E T N^{7}\right)$ El signo es un lazo, una relación entre dos cosas:un conceptoy una imagen acústica, es decir, un significado y un significante. Tiene dos características esenciales: la arbitrariedad y la linealidad del significante. Los signos no son abstractos, sino objetos reales, son las entidades concretas estudiadas en la lingüística; dichas entidades deben estar delimitadas, es decir, ser unidades que se opongan a otras en el mecanismo de la lengua, ya que en esta, como en todo sistema semiológico, 10 que distingue a un signo es lo que constituye; un signo es una forma no substancia.- A decir de Leach, el signo corresponde a una relación metonímica, es decir, a una asociación sintagmática. Símbolo, semiótica, semiología (Ibídem, 2000).

El signo representa el punto de partida para el debate antropológico entre la cognición del símbolo y su estructura condensada; bajo la acepción de términos, conceptos y significados, se retoma el siguiente fragmento:

Símbolo: (AS) (ETN) De acuerdo con Geertz, este término se usa para designar cualquier objeto, acto, hecho, cualidad o relación que sirva como vehículo de una concepción, donde la concepción es el significado del símbolo. A partir de Leach, el símbolo es metáfora, es decir, corresponde a una relación paradigmática. Por su parte Lévi Strauss afirma que los símbolos tienen efecto de signos cuando son demasiados convencionales en una cultura. En los estudios de Turner sobre el ritual, el símbolo aparece como la unidad más pequeña de éste. Signo, semiótica, semiología (Ibíd., 2000).

\section{Las huellas que se impregnan en el sendero de la metodología}

Se implementó el método etnográfico con el auxilio de la técnica de la encuesta para complementar, a nivel estadístico, las percepciones de estudiantes de la cátedra de Filosofía, quienes comparten dicho espacio académico en el fortalecimiento de los pre-saberes, unificándolos con los nuevos conocimientos, tomando en cuenta que el perfil de dichos estudiantes es variado, ya que cursan diferentes carreras, lo cual permite un abordaje amplio del tema a partir de las percepciones de cada uno de ellos, a través de los datos cuantitativos.

Para tal efecto, la consulta de fondos documentales marcan las premisas en el investigador sobre aquellos elementos que puede llegar a observar o que posiblemente han quedado en la memoria colectiva de los informantes claves, de quienes se obtiene el registro de datos cualitativos sobre las experiencias vividas en la sociedad donde está inmerso; así mismo, la generalidad del pensamiento humano y de su universalidad se puede distinguir mediante el registro de datos cuantitativos; de ahí la importancia del método o de los métodos que se han de elegir para el registro de los hallazgos de campo.

Ilustración 1. Esquema conceptual sobre la metodología de investigación en las Ciencias Sociales, retomado de apuntes de clases de la asignatura de Teoría de las Formaciones Sociales a cargo del Lic. Óscar Sánchez, sociólogo y docente de la Escuela de Antropología Utec. Ciclo académico 02/2015. Diseño realizado por Miguel Ángel Hernández Vásquez.

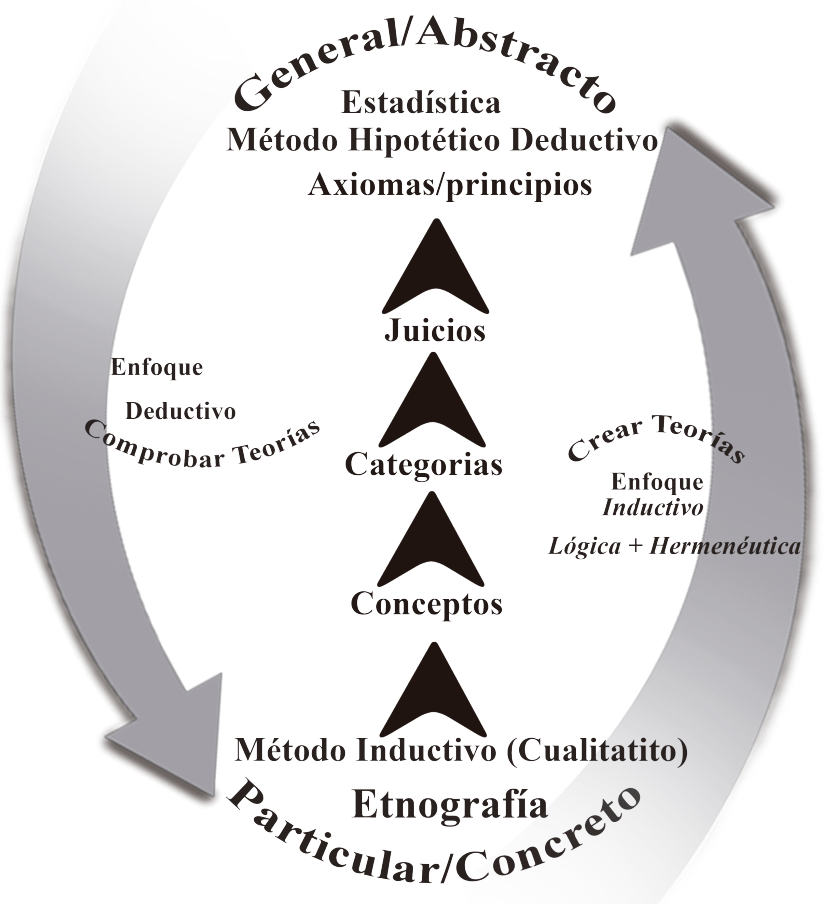

\footnotetext{
5 Lingüística

${ }^{6}$ Antropología Social

7 Etnología
} 
Tal como aparece en la figura 3, las características de ambos enfoques permiten hacer un abordaje de lo abstracto a lo concreto desde el enfoque deductivo; mientras que, desde el enfoque inductivo, el abordaje de los fenómenos sociales en estudio parte de lo concreto a lo abstracto, de lo particular a lo general. En ambas direcciones es importante hacer un abordaje inter y multidisciplinario. sin embargo, para el presente ejercicio etnográfico se ha realizado el préstamo de la técnica de la encuesta del método cuantitativo para establecer una aproximación a las realidades de los sujetos emics.

\section{La discusión de los resultados a través de la investigación etnográfica}

Para complementar el análisis y la interpretación de los datos cualitativos obtenidos en las conversaciones y entrevistas guiadas, se aplicó un test de encuesta dirigida a la población estudiantil que cursó la asignatura de Filosofía, en el ciclo 02/2015, población considerada como finita, ya que representa menos de 1000,000. Dicha población equivale
El tamaño del universo es de 460 estudiantes, por tanto, al aplicar la fórmula anteriormente descrita, dio como resultado 211 encuestas que se suministrarían para la presente muestra, tomando en cuenta un margen de error de $5 \%$, cuyo nivel de confianza es del $95 \%$, para la validación de hipótesis, a través de la prueba con chi-cuadrado.

\section{Discusión sobre las hipótesis de investigación}

Según los datos obtenidos en la aplicación de un test de encuesta estructurado en dos partes: la primera, de preguntas dicotómicas nominales, y la segunda, de preguntas bajo la escala de Likert ordinal, el nivel de confianza establecido fue de $95 \%$, mientras que el margen de error se estableció del $0,05 \%$, el cual representa el $\alpha$. En ese sentido, al tabular los datos obtenidos durante la aplicación del instrumento a la población total de 211 estudiantes de la cátedra de Filosofía de la escuela de Antropología de la Utec, se obtuvo el nivel de significancia de 0,00 \% que resultó al procesar dichos datos con el programa SPSS, cuyo nivel de significancia utilizado para validar las dos hipótesis planteadas fue menor $\alpha$.

Tabla 1. Prueba de hipótesis de investigación, utilizando la prueba de chi cuadrado, usado frecuentemente en Ciencias Sociales para investigaciones cuantitativas de carácter no probabilístico

\begin{tabular}{lccc}
\hline & Valor & gl & Sig. asintótica (bilateral) \\
\hline Chi-cuadrado de Pearson & $1.800 a$ & 3 & .615 \\
Razón de verosimilitudes & 1.807 & 3 & .613 \\
Asociación lineal por lineal & .135 & 1 & .714 \\
N de casos válidos & 211 & & \\
\hline
\end{tabular}

a. 0 casillas $(, 0 \%)$ tienen una frecuencia esperada inferior a 5. La frecuencia mínima esperada es 15.13.

Elaboración propia

a 460 estudiantes activos en dicho ciclo. Por lo consiguiente, como parte de una prueba piloto no probabilística, utilizando la fórmula de población finita, esta dio como resultado una muestra de 211 encuestas, para el registro a nivel cuantitativo, sobre el conocimiento y percepciones que tienen los y las estudiantes que cursan la asignatura de Filosofía en la Utec acerca de los orígenes del tatuaje; a quienes se les consultó sobre las percepciones que tienen con respecto al tatuaje en sus diferentes estilos artísticos y simbólicos.

Tomando en cuenta la fórmula de población finita, se retomaron los siguientes aspectos considerados para el presente ejercicio etnográfico, la cual se presenta a continuación.

Para poblaciones finitas (menos de 100.000 habitantes):

$$
\mathbf{n}=\mathbf{Z 2} * \mathbf{P} * \mathbf{Q} * \mathbf{N} / \mathrm{e} 2(\mathbf{N}-1)+\mathbf{Z 2} * \mathbf{P} * \mathbf{Q}
$$

\section{El elemento estructural lingüístico en el tatuaje}

Cada palabra que cotidianamente expresan verbalmente los seres humanos tiene sus orígenes en las fuerza creadora que emite de la motricidad gruesa y fina de sus manos; se hace alusión a la percusión como parte del ensayo prueba y error, en el cual tiene su génesis cuando se habla del desarrollo de las diferentes culturas, las cuales establecen sus estrategias metodológicas en la concreción de sus contextos históricos y particulares. En lo anterior se manifiesta la importancia de la lingüística en la pronunciación y asociación del elemento simbólico del sonido que surge en cada golpe de percusión a nivel quirúrgico en la práctica del tatuaje. En palabras de Ramón Umaña (2015), alias Noone, se distingue el siguiente comentario: 
Se le llamaba Tao, tao, tao por el golpe tao tao entonces hay descendido la palabra "tatto" golpe tao tao como decir tatto... Entonces era un palito... un palito (que servía de martillo ${ }^{8}$ ) con otro palito (que servía de extensión) que tiene una espinita en su interior... y lo que hace es al momento de iniciar el tatuaje, emitir el sonido pack pack pack pack (Umaña, 2015).

Figura 1. El tatuaje en proceso imagen tomada de www. facebook.com/noone.umana?fref=photo

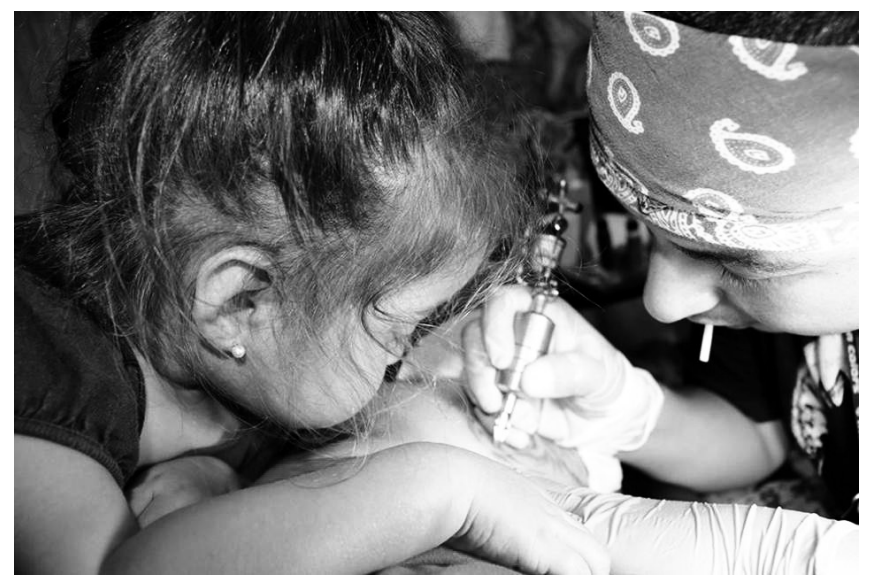

En la asociación del elemento onomatopéyico con la historización de los conceptos es importante identificar en el imaginario colectivo de los expertos culturales? ${ }^{9}$, para dimensionar la práctica y la evolución del tattoo y sus variantes lingüísticas, que se expresan a través del dialecto y de los idiolectos en las diferentes zonas geográficas en donde se ha desarrollado dichas prácticas corporales.

Percepciones de la comunidad estudiantil entorno al tatuaje y sus orígenes

En dicha encuesta, al preguntarles a los estudiantes de Filosofía si conocen los orígenes del tatuaje, más del 70 \% de los 211 encuestados(as) respondió desconocerlo, sin embargo, solo el
22,7 \% respondió que sí lo conoce.

Por lo consiguiente, se presenta la siguiente tabla de frecuencias.

Sin embargo, al separar por género la consulta hecha a los 211 estudiantes de ambos sexos, sobre si conocían el origen del tatuaje, en total el 77,3 \% respondió que no. Caso contrario, al observar los porcentajes de quienes sí lo conocen, la mayoría son hombres, reflejándose en un 13,74 \%, ante un leve porcentaje del 9,0 \% de mujeres que también respondieron tener dicho conocimiento. Los datos se presentan a continuación:

Gráfico 1. Variable por género sobre conocimiento acerca del tatuaje

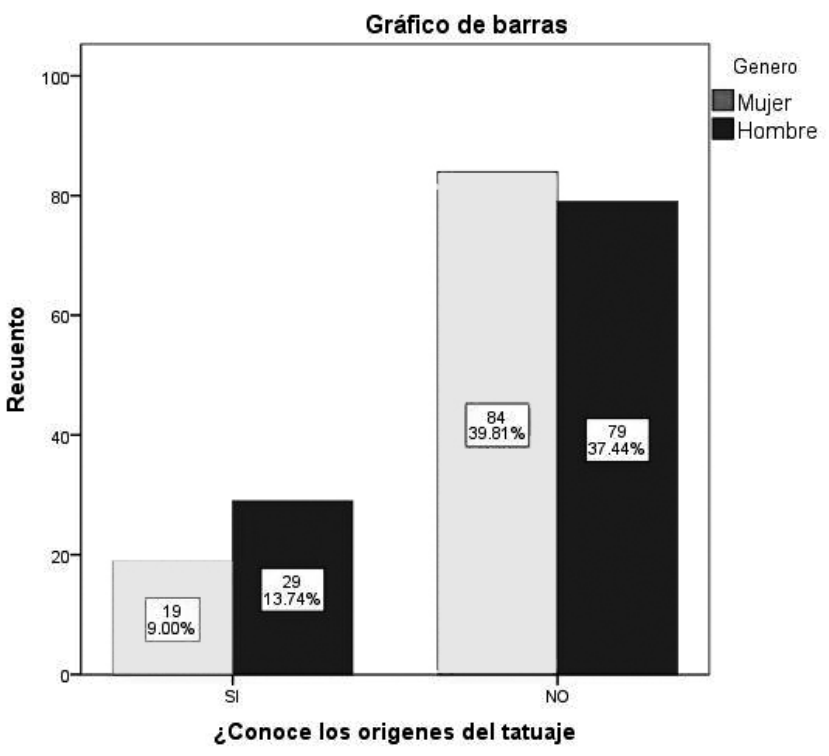

Así mismo, el simbolismo está presente en el estilo y formas del tatuaje, los cuales a su vez están relacionados con las escuelas de aprendizaje a nivel generacional en los tatuadores, y su práctica de su diseño, tal como se expresa en el siguiente aporte:

Tabla 2. Conocimiento sobre los orígenes del tatuaje

\begin{tabular}{rcccc}
\hline & Frecuencia & Porcentaje & Porcentaje válido Porcentaje acumulado \\
\hline Validos Sí & 48 & 22,7 & 22,7 & 22,7 \\
No & 163 & 77,3 & 77,3 & 100,0 \\
Total & 211 & 100,0 & 100,0 \\
\hline
\end{tabular}

Elaboración propia

\footnotetext{
8 Para efectuar el golpe de percusión.

9 Informantes claves.
} 
Figura 2. El búho y su simbolismo en el arte del tatuaje. Fotografía proporcionada por Ramón Umaña

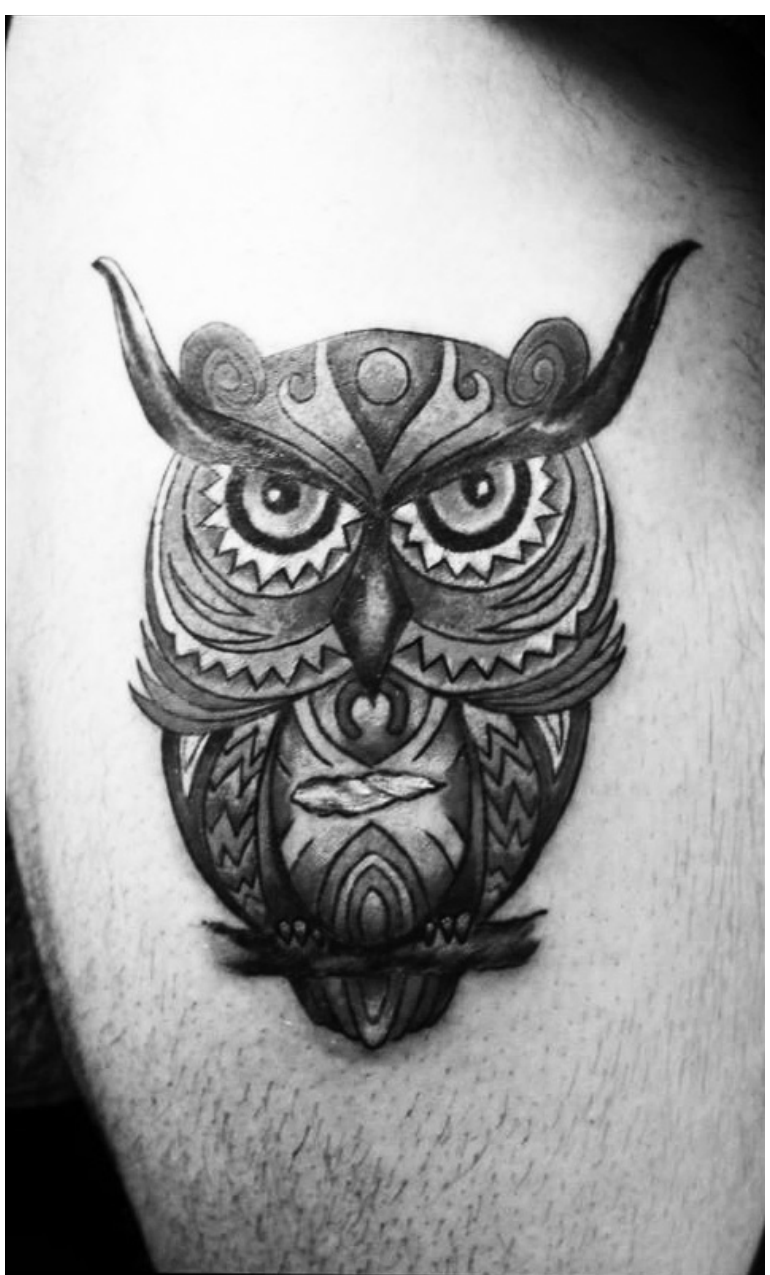

El caso el tatuaje se vuelve un símbolo de pertenencia, igual es un signo que puede marcar un lenguaje determinado... desde el punto de vista semiótico lo que Saussure plantea, como la interpretación de la comunicación... es en grupos de pertenencias, lo que sacó de una de sus hipótesis relacionada con el lenguaje, donde marca, ${ }^{10}$ que a la larga es el lenguaje, es cultura que notas, y de valores culturales... en este caso el tatuaje es parte de ese elemento, de ese lenguaje que transmite valoraciones y significados como Saussure lo planteaba en el significado, la parte del tatuaje que es significante en sí (Sermeño, 2015).

Tal como se observa en la figura 2, el elemento simbólico del búho representa el centinela o vigilante nocturno, que se puede interpretar desde diferentes perspectivas o sistemas de creencias. Por ejemplo, se asocia con la inteligencia, con la fortaleza ante la incertidumbre por considerarse como un ser nocturno y sigiloso que se resguarda en la oscuridad y en la tranquilidad de la noche y de las tinieblas, que sale avante ante cualquier situación adversa, ya que no se adelanta a los hechos, por el contrario, se mantiene a la expectativa de todo lo que sucede a su alrededor.

Por otra parte, al realizar la consulta a los y las estudiantes de Filosofía, mediante las encuestas suministradas, se puede observar en la escala de frecuencia que el 77,3\% de los encuestados(as) expresaron desconocer el significado de la palabra tatuaje, mientras que el 22,7\% restante expresó conocer dicho significado, tal como se muestra en la siguiente tabla de frecuencia.

Al observar la variable de género sobre quienes tienen conocimiento de los orígenes del tatuaje, la mayoría de los que respondieron que sí son hombres, reflejándose en un 13,74 \%, caso contrario el de las mujeres, de las que solo un 9,0\% respondieron que sí tienen conocimiento.

\section{Tabúes y estigmas sobre la adoración al cuerpo a través del tatuaje}

Cada sociedad configura sus pensamientos a partir de los paradigmas que condensan sus formas de vida y prácticas cotidianas, reproduciéndolas y manteniéndolas vigorosas, cuando la norma establece las reglas que hay que seguir al pie la letra para mantenerse como miembro de la sociedad a la cual se pertenece.

Tabla 3. Conocimiento sobre el significado de la palabra tatuaje

\begin{tabular}{rcccc}
\hline & Frecuencia & Porcentaje & Porcentaje válido & Porcentaje acumulado \\
\hline Validos Sí & 48 & 22,7 & 22,7 & 22,7 \\
No & 163 & 77,3 & 77,3 & 100,0 \\
Total & 211 & 100,0 & 100,0 & \\
\hline
\end{tabular}

Elaboración propia

10 Se entiende la marca en este contexto como las líneas, trazos, figuras y colores que encierran el diseño de un tatuaje. 
Dichas reglas se condicionan en un sistema de prohibiciones que están caracterizados por el tabú, y que se complementan mediante los estigmas que encajonan la visión del ser humano en una dirección parcializada de la realidad en que vive. Es importante resaltar los elementos simbólicos, que se expresan en el imaginario individual y colectivo de cada sociedad, tal como expresó uno de los expertos culturales en el siguiente argumento:

La adoración al cuerpo es milenario... sino a la gente no hubiera hecho, en la antigüedad... va era gente normal que guiaba los pueblos, pero dicen... "que era un semidiós" verdad porque si decian que era un civil no lo iban a respetar lo iban a ver nada más, y que era el gran héroe verdad... entonces siento que la adoración al cuerpo lo puedes ver en diversas partes; en una iglesia cuando ves a un Cristo guindado y ves que es una persona que nos sabes si era esa similar igual, ya si era moreno, negro que se yo, pero estas ahí, en ese lugar, aunque no te arrodilles... estás viendo un cuerpo, que esta flagelado, por ende lo respetas y le dedicas un culto y tiempo... la evocación al cuerpo uno es muy importante porque es como auto-respetarse el hecho de tomar y fumar es no querer tu cuerpo, es darle respeto que se merece, no lo digo por Dios lo digo por vos porque va a adorar menos aquí (Umaña, 2015).

Los ritos de paso y la performatividad también están presentes en la práctica del tatuaje, tal como lo expresa Ramón Umaña en el siguiente fragmento:

El tatuaje era como un ritual... era más ritual por la misma adoración al cuerpo o sea la adoración del cuerpo siempre va de la mano... con respecto al tatuaje porque tú te haces algo para lucirlo, a excepción de que tu mamá o tu papá tenga un estigma contigo, no lo muestras, pero a tus amigos sí, entonces escomo que alguien te reconozca por eso y te hace ver más o menos bonito vea para el sexo opuesto (Ibídem., 2015).

El sistema de creencias siempre acompaña la cotidianeidad en el ser humano, algo que refleja ese constructo de ideas conservadoras o liberales entorno a lo considerado como moral o ético en la sociedad, ante lo adverso que es considerado como inmoral o antiético; sobre todo cuando se trata de interpretar el significado del tatuaje y su simbología.

Por su parte Aksy Cortez, una joven estudiante de 28 años de edad, también egresada de la Licenciatura en Artes Plásticas de la UES, y de origen turco, pero radicada en el país hace más de 8 años, expresó lo siguiente respecto al tema del tabú inmerso en el tatuaje y su práctica:
Figura 3. Entrevista guiada con Ramón Umaña, egresado de la licenciatura en Artes Plásticas opción Diseño Gráfico, Escuela de Artes de la Universidad de EL Salvador (UES).

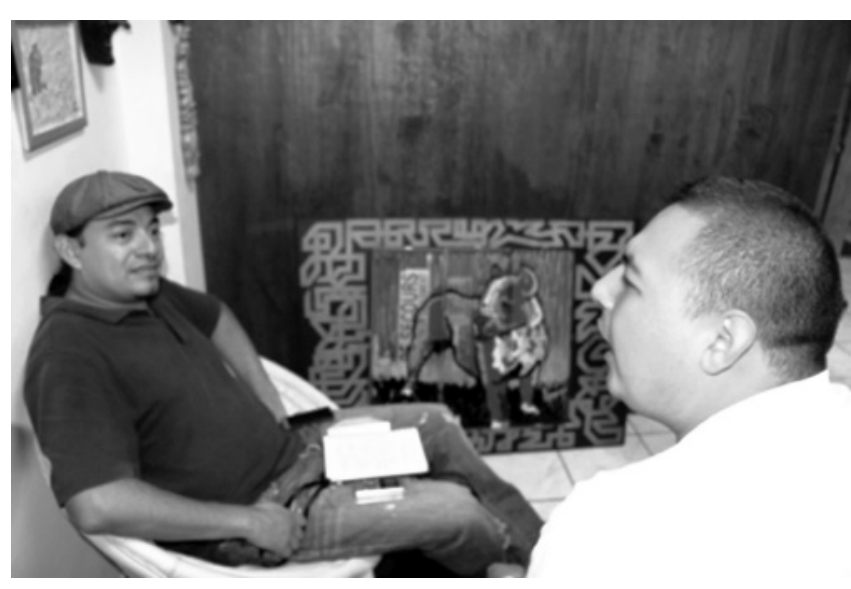

En Turquía, como católicos y evangélicos, tiene algo que, cuando tú haces eso, significa que es un pecado... Entonces no es, por una parte, esa religión, prácticamente está saliendo como un rebelde de todo; eso entonces intencionalmente hice; porque en estas están diciendo, me obligan, y me están diciendo no, pero es pecado... A mis 17 años hice mi primer tatuaje, porque mi familia [...] como algunos toman la decisión de tatuarse como reputación en representa algo malo de una persona [...] Dicen que no se hacen tatuajes, pero, o yo salí un poco rebelde, y también tenía ese conflicto con la religión, especialmente en mi país, como noventa por ciento son islámicos... También lo hice por eso que represente esa contradicción que no me gusta la religión... Por eso represente en mi primer diablo y de rebeldía contra mi familia (Cortez A. , 2015).

Figura 4. Entrevista guiada con Aksy Cortez, estudiante de 5. año de la Licenciatura en Artes Plásticas opción Pintura, escuela de Artes, UES.

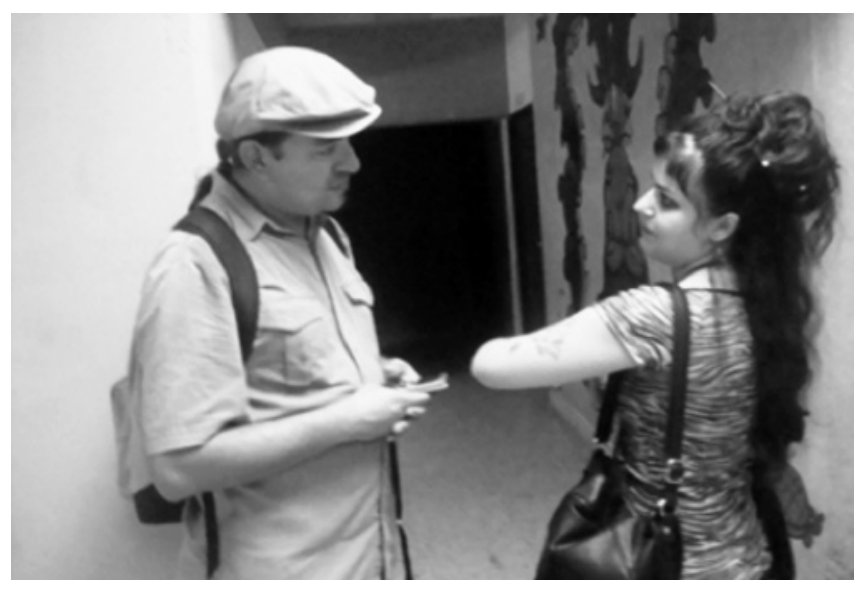


Tabla 4. Percepciones sobre el tatuaje y su relación con los diferentes estratos sociales

\begin{tabular}{ccccc}
\hline & Frecuencia & Porcentaje & Porcentaje válido & Porcentaje acumulado \\
\hline VálidosDelincuencia & 46 & 21,8 & 21,8 & 21,8 \\
Estatus social & 32 & 15,2 & 15,2 & 37,0 \\
Moda & 114 & 54,0 & 54,0 & 91,0 \\
No sabe & 19 & 9,0 & 9,0 & 100,0 \\
Total & 211 & 100,0 & 100,0 & \\
\hline
\end{tabular}

Elaboración propia

Por otra parte, retomando los resultados obtenidos a traves de la técnica de la encuesta, se presenta la siguiente tabla de frecuencia sobre las percepciones que tienen los estudiantes de la asignatura de Filosofía con respecto a los estratos sociales, el status y la moda que representa el tatuaje y su práctica.

Tal como se observa en la tabla anterior, el primer lugar lo ocupa el 91,0 \% de los encuestados(as), quienes relacionan el tatuaje con la moda; seguido de un $21,8 \%$ de quienes lo relacionan con la delincuencia; la tercera casilla la ocupa el status social, el cual representa el 15,2 \% de la muestra total de 211 estudiantes que contestaron el cuestionario de preguntas dicotómicas y politómicas.

Finalmente, el uso de la tecnología facilita los antiguos y complicados procesos quirúrgicos del proceso en el tatuaje, a tal grado que el estigma de contraer el VIH al momento de tatuarse es solo una referencia histórica de las antiguas prácticas, bajo condiciones infrahumanas, como lo era al interior de una cárcel, en donde no se podía acceder a equipo tecnológico quirúrgico adecuadamente esterilizado. Los nuevos espacios llamados estudios Tattoo, tienen esa característica de ofrecer a las personas interesadas en tatuar su cuerpo, un espacio digno y adecuadamente iluminado para dicha práctica, un elemento que resalta el tatuador Umaña en el siguiente fragmento:

O sea, ahora es bien diferente al material hechizo, bien diferente porque la aguja no venía sellada, aquí la gente puede tener la certeza que los materiales están esterilizados... que pueden buscarnos y ver su fecha de expiración porque todo expira hasta las agujas (Ibíd., 2015).

Así mismo, al hablar sobre el aspecto inmoral o antiético que todo profesional, independientemente de su especialidad o área laboral, deba o no tatuarse el cuerpo; de los 211 encuestados, entre hombres y mujeres, coincidieron en que no es inmoral el tatuarse el cuerpo, reflejándose en un 44,07 $\%$. Caso contrario, los que opinaron que sí es inmoral el que un profesional se tatué su cuerpo se refleja en un $21,80 \%$.
Esto puede interpretarse como una apertura a la práctica del tatuaje.

Figura 5. Equipo e instrumentos que integran la máquina para tatuar, así como sus demás instrumentos auxiliares para evitar infecciones y desinfectar el área tatuada. Fotografía tomada por Ramón Umaña.

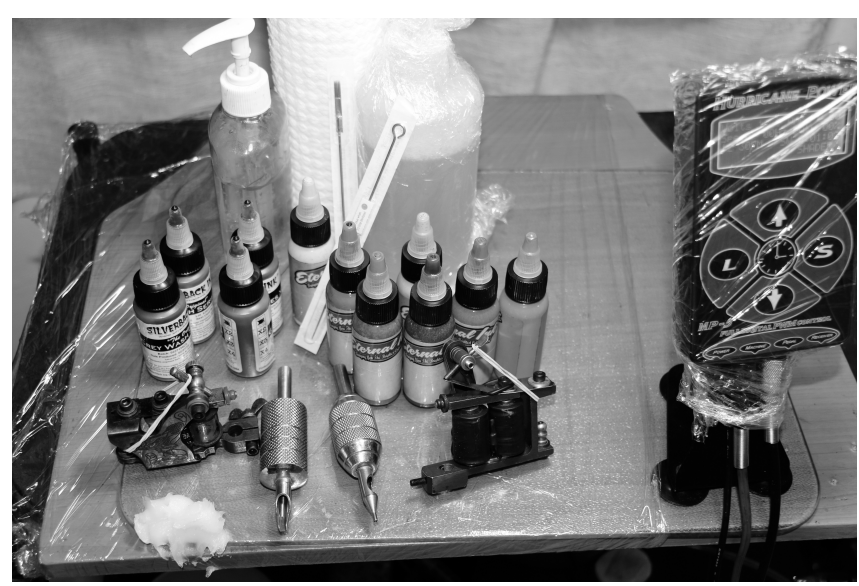

Dichos resultados se presentan en el siguiente gráfico.

Gráfico 2. La moralidad y la ética de un profesional que use tatuaje

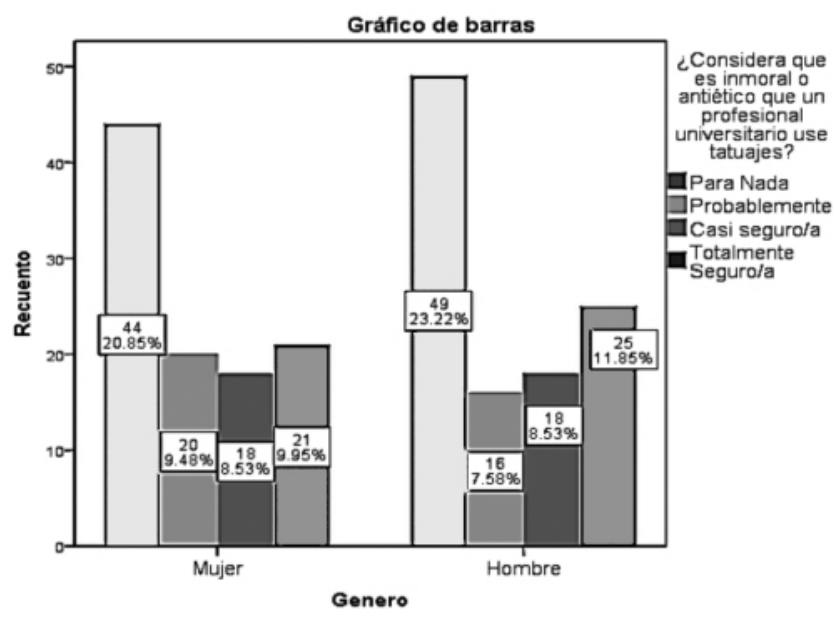




\section{Conclusiones}

- Las tribus urbanas (subculturas) y las contraculturas (las pandillas) son los principales grupos étnicos que consumen el arte del tatuaje, y de ahí su simbolismo y quehacer cotidiano en la sociedad, como reproductores del sistema capitalista o como agentes activos que inciden en la sociedad en el rompimiento de viejos paradigmas.

- La evolución del tatuaje en sus diseños, formas, contenidos y estructuración estética guarda una estrecha relación con las corrientes artísticas propias de las artes plásticas, como lo es actualmente la influencia del tatuaje tribal, de la técnica de la acuarela, del surrealismo y, recientemente en boga, el hiperrealismo, como parte de la estética que guardan las expresiones plásticas como medio de comunicación.

- En la sociedad salvadoreña del siglo XXI persisten los tabúes con respecto al simbolismo que representa el tattoo ante los esquemas religiosos y los estigmas que circundan al contagio del VIH, mediante el proceso quirúrgico que se realiza en el proceso del tatuaje, mediante la esterilización del equipo, sobre todo de la aguja, que es el punto clave en estos prejuicios, tabúes y estigmas.

\section{Referencias}

Cortez, A. (2015, 22 de octubre). [Entrevista con M. Á. Hernández Vásquez: Tabúes en el tatuaje]. Grabación de audio.

Cortez, C. (2015, 22 de octubre). [Entrevista con M. Á. Hernández Vásquez: El tabú del tatuaje y su simbolismo]. Grabación de audio.

Eco, H. (1988). Signo (2da. Ed). Serra Cantarell, F. (Trad). Barcelona, España: Labor.

Hope Ponce, M. E., \& Mora Eguiarte, D. (2000). De abominable a zubiburrico. Diccionario de Antropología en la ENAH. México D.F.: ENAH.

Sastre Cifuentes, A. (2011, enero-junio). Cuerpos que narran: la práctica del tatuaje y el proceso de subjetivación. Diversitas: Perspectivas en Psicología. 7 (1), 179-191.

Sermeño, Á. (2015, 17 de octubre). [Entrevista con M. Á. Hernández Vásquez: El tatuaje y su relacion con las artes plásticas]. Grabación de audio.

Strauss, C. L. (1987). Antropología estructural (1ra. Ed). Buenos Aires: Paidós.

Umaña, R. (2015, 19 de octubre). [Entrevista con M. Á. Hernández Vásquez: El arte del tatuaje]. Grabación de audio. 